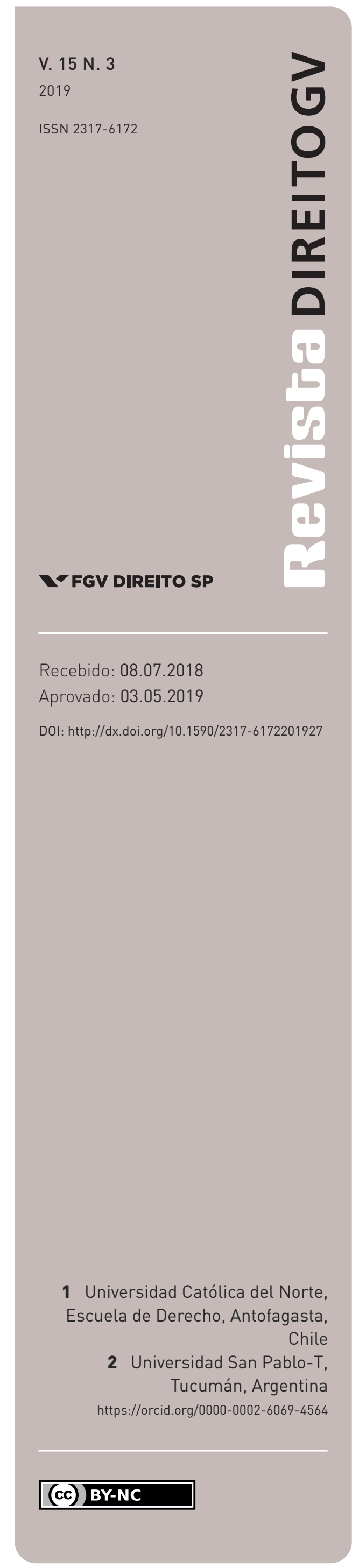

\section{Hacia una apelación óptima: acceso y gerenciamiento de la segunda instancia}

\author{
TOWARDS AN OPTIMAL APPEAL: ACCESS AND CASE MANAGEMENT OF SECOND INSTANCE \\ RUMO A UM APELO OPTIMIZADO: ACESSO E GERENCIAMENTO DA SEGUNDA INSTÂNCIA
}

Alvaro Javier Pérez Ragone $e^{\mathbf{1 , 2}}$

\section{Resumen}

La atención que los tribunales de alzada en apelación pueden prestar a los casos que conocen se ha convertido en un "recurso escaso". Aplicando la metodología del Análisis Económico del Derecho combinada con muestras del derecho comparado y examen dogmático se persigue validar en este artículo dos hipótesis: la primera relacionada con la necesidad de criterios discrecionales y objetivos de selección de casos apelables; la segunda, consecuencia de la primera, sostiene que solo así es posible un adecuado gerenciamiento de esos casos seleccionados en segunda instancia ex post. El derecho al recurso de apelación en material civil no es absoluto y puede ser limitado. Esta propuesta es como una tercera vía que optimiza la apelación y distribuye proporcionalmente las externalidades negativas y positivas del recurso. Con el argumento de que la apelación no está destinada únicamente a corregir errores que afectan a uno de los litigantes, esta parece ser una premisa necesaria de los beneficios infinitos para el sistema y los litigantes, que pueden proporcionar una apelación optimizada.

\section{Palabras clave}

Apelación; optimización; filtros; gerenciamiento; audiencias.

\begin{abstract}
The attention that courts of appeal on appeal can give to cases they know has become a "scarce resource". Applying the methodology of Law \& Economics combined with samples of comparative law and dogmatic examination, this article aims to validate two hypotheses: the first one is related to the need of discretional criteria and the selection objectives of appealable cases ex post. The second, consequence of the first, is that only in this way is possible to properly manage those cases selected in the second instance. This proposal is like a third way that optimizes the appeal and proportionally distributes the negative and positive externalities of the resource. Begin by arguing that the remedy does not have as its sole objective the correction of errors that affect one of the litigants seems to be a necessary premise that infers the multiplicity of benefits for the system and for the litigant, that can provide an optimal appeal.
\end{abstract}

\section{Keywords}

Appeal; optimal appeal; filters; case management; hearings.

\section{Resumo}

A atenção que os tribunais de recurso podem dar aos casos que conhecem tornou-se um "recurso escasso". Aplicando a metodologia de Law \& Economics, combinada com amostras de direito comparado e exame dogmático, o objetivo deste artigo é analisar duas hipóteses: a primeira está relacionada com a necessidade de critérios discricionários e objetivos para a seleção dos casos passíveis de recurso; a segunda hipótese, consequência da primeira, é que somente dessa maneira seja possível gerenciar adequadamente os casos selecionados na segunda instância ex post. Essa proposta é uma terceira maneira de otimizar o recurso e distribuir de modo proporcional as externalidades negativas e positivas dele. Com o argumento 
de que o recurso não tem como único propósito a correção de erros que afetam um dos litigantes, esta parece ser uma premissa necessária da infinidade de benefícios para o sistema e para os litigantes, que podem fornecer uma apelação otimizada.

Palavras-chave

Apelação; otimização; filtros; gerenciamento; audiências.

\section{INTRODUCCIÓN}

El objetivo general de esta investigación es el adecuado gerenciamiento de casos en la segunda instancia. Para ello se presta atención al (i) mecanismo de selección de casos para una segunda instancia civil en un modelo de procesos por audiencia (ii) para poder aplicar a esos casos meritorios adecuadas técnicas de conducción y dirección para una sentencia de mayor calidad. La atención que los tribunales de apelación (al igual que los jueces de primera instancia civil) pueden prestar a los casos que conocen se ha convertido en un "recurso escaso". La sobrecarga de los tribunales de apelación a nivel comparado es una realidad que conspira contra una adecuada conducción y un gerenciamiento específico de la segunda instancia que tiene especialidades propias diferenciadoras de las de la primera instancia por audiencias. El derecho al recurso de apelación en material civil no es absoluto y puede ser limitado. Deben así buscarse criterios adecuados de filtros de acceso al recurso tanto en primera como en segunda instancia que puedan garantizar a menores recursos humanos e infraestructurales que en primera instancia, además de un funcionamiento óptimo, y que brinden un servicio de justicia eficaz y eficiente (CARRINGTON, 1987, p. 411-415).

Este artículo explora la necesidad de limitar el acceso a la apelación para optimizarla en tanto una sobrecarga de la alzada genera externalidades negativas (daños) desde una perspectiva económica que, internalizadas por quienes las producen, instan a determinadas conductas tanto de los litigantes como de los tribunales. Por el contrario, con las propuestas que se explicarán y ejemplificarán del derecho comparado se producen externalidades positivas (beneficios) que redundan en una mejor distribución de costos, perjuicios y beneficios en el sistema (MCCLUSKEY, PASQUALE, TAUB, 2016; KORNHAUSER, 2000, p. 47-50). En los modelos comparados que se examinarán priman dos tipos de filtros, uno en el a quo (reducido normalmente a la cuantía o monto discutido), y otro en el ad quem, donde salvo el modelo francés se evalúa la posibilidad cierta de éxito del recurso ex ante (si es un caso meritorio). El problema está en cómo se determinan y si deben ser soportados en igual medida tanto por el buen como 
por el mal litigante, tanto por una corte de apelación eficiente como por una ineficiente (PORAT, 2009, p. 189).

Una vez que solo accedan a la alzada casos meritorios de ser conocidos en un modelo de primera instancia por audiencia fuerte, una segunda instancia revisora limitada, pero con posibilidades de inmediación y contacto de los jueces de alzada con las partes mediante audiencias de vista, se optimiza la apelación. Ahora el problema está en qué momento se determina lo “meritorio" del caso, como filtro en el ad quem. En el modelo alemán, austríaco, inglés e italiano, integra la fase de la admisibilidad del recurso, es decir es ex ante. Se sostiene así que reduce el ingreso indiscriminado de causas para que los tribunales de alzada cumplan un rol de control y revisión limitado también de calidad concentrado a casos con relevancia para generar un producto con externalidades positivas y no aplicar los recursos más escasos en la alzada a procesos que por su naturaleza o presuntamente por su monto se justifica que sean de instancia única (WILNER, 1968). A este requisito limitante se suma el incentivo negativo de la posibilidad de ejecución provisional de la sentencia como mecanismo disuasivo que compensa la eficacia de los derechos inmediato y al mismo tiempo disuasivo del uso abusivo de la apelación. El problema es que hay que generar mecanismos para el control de ese examen discrecional en segunda instancia. El modelo ex ante prima, en Alemania con buenos resultados, por el contrario, su importanción, como por ejemplo en Italia, ha generado en la doctrina mucha crítica por limitar el acceso al recurso segundo examen de admisibilidad que es competencia del superior.

La conducción y el gerenciamiento de un proceso judicial imponen un trato efectivo, eficiente y útil a un caso en concreto, para así lograr su resolución, oportuna y justa, sin dejar de considerar el peso de otros posibles casos o procesos por ingresar o pendientes de ser resueltos en un sistema eficiente de justicia (CAUTHEN, LATZER, 2008). La identificación temprana de cuestiones disputadas sobre hechos y derechos, el establecimiento de un calendario procesal para el caso y la exploración de la posibilidad de resolución de una disputa a través de métodos distintos al adjudicativo son otros puntos a tener en cuenta (ZUCKERMAN, 2009, p. 105). Corrientes modernas han buscado darle herramientas de conducción efectiva a los tribunales (POSNER, 2006, p. 1049-1050), sumar a ellos necesariamente en la segunda instancia las nuevas tecnologías, no renunciar a incentivar vías autocompositivas internas o incluso derivación a mediación. Finalmente y en caso de llegarse a una sentencia, que esta sea de mayor calidad y justa. Así es posible sostener, y este estudio parte de esta hipótesis a corroborar, que la limitación al acceso a la apelación civil no solo es jurídicamente válida, sino necesaria en un sistema de procesos por audiencia donde la calidad de la decisión es más elevada y menos falible en primera instancia (NOBLES, SCHIFF, 2002, p. 676). Se parte por defender los filtros de admisibilidad en primera instancia ex ante y postular los de segunda ex post combinando criterios objetivos y discresionales de los tribunales.

Desde fines del siglo XIX estaba abierta una fuerte discusión sobre el rol del juez en el proceso civil en Europa y en los países que iban adquiriendo su independencia en Latinoamérica. 
En términos generales, podría decirse que el sistema judicial establecido en códigos, luego de la Revolución Francesa, y hasta parte del siglo XX, se caracterizó por un entendimiento privatista e individualista de los fines del proceso (KOURLIS; KAUFFMAN, 2015, p. 494-500). Para este entendimiento del proceso, los autores comenzaron a llamar como "principio dispositivo" el rol primordial reservado a las partes como dueñas del proceso (LANGBROEK, 2017, p. 1-2). La principal contribución en la reacción al puro "dejar hacer" consistió en poner la atención en el rol público-social de una controversia civil (BETTINGER, 2016, p. 3-8). La proactividad se manifestó en dos aspectos: (i) el objetivo social era el de equiparar materialmente a las partes, controlando la superioridad social o económica de una de ellas que podría, sin control, traducirse en superioridad procesal (TURNER, 2004, p. 73-88); (ii) al mismo tiempo, se buscó a través de la administración del proceso evitar retardos o comportamientos obstructivos de las partes (LANGBROEK, 2017, p. 1-2). Como Andrews comenta, el case management tiene tres principales funciones en el siglo XXI tanto en primera como en segunda instancia: alentar a las partes a buscar una solución mediante la mediación, siempre y donde sea practicable; segundo, prevenir que el proceso progrese demasiado lento e ineficientemente; finalmente, asegurar que recursos judiciales sean asignados proporcionalmente, como lo requiere 'el Objetivo Primordial' de CPR parte 1 (reformulado en 2013 para destacar la necesidad de que los casos sean tratados con costos justos y proporcionales)"1 (ANDREWS, 2017).

Aplicando la metodología del Análisis Económico del Derecho Procesal (AEDPR) combinada con muestras del derecho comparado y examen dogmático se persigue validar dos hipótesis: la primera relacionada con la necesidad de criterios discrecionales y objetivos de selección de casos apelables; la segunda, consecuencia de la primera, sostiene que solo así es posible un adecuado gerenciamiento de esos casos seleccionados en segunda instancia. Esta propuesta es como una tercera vía (entre apelación amplia e inexistencia de apelación) que optimiza la apelación y distribuye proporcionalmente las externalidades negativas y positivas del recurso. Considero que el examen en la segunda instancia debiera hacerse no ex ante como parte de la admisibilidad, sino ex post en la decisión del recurso. Así, si se ha tratado de un caso "no meritorio", existe la posibilidad de imponer costas y multas contra el recurrente que incurrió en el abuso. Con ello, el foco de atención se centra en el segundo filtro, que se termina plasmando luego de tramitar el recurso y en la decisión de mérito de la alzada. Este artículo se compone de las siguientes partes: en una primera (1), se detallan los antecedentes del "case management" o "gerenciamiento o dirección del proceso"; luego se analizan los límites para el acceso a la apelación desde diferentes puntos críticos (2); se sigue con el

1 Andrews, Neil. English Case Management System (Report England), London: Inédito, 2017, citando las reglas inglesas "CPR 1.1(1): These Rules are a new procedural code with the overriding objective of enabling the court to deal with cases justly and at proportionate cost". 
análisis del gerenciamiento de casos en segunda instancia mencionando sus principales desafíos y herramientas (3); se concluye con unas reflexiones.

\section{ANTECEDentes Del CaSE management EN GENERAL}

La doctrina y visión detallada de la necesidad de "conducción, dirección y gerenciamiento de los procesos”, luego de 1939, se desarrolló en el mundo Anglo-Americano con los términos muchos más amplios de "case management" (CHAYES, 1976, p. 1281). Van Rhee (VAN RHEE, 2005, p. 3-13) pone énfasis en que la influencia del código francés de 1806 fue, mayormente, apoyar un enfoque de laissez faire de la litigación, bajo la cual los litigantes y los abogados (no los jueces) controlan el contenido y el progreso de los casos. El código austríaco de Franz Klein, introducido a finales del siglo XIX, estaba más orientado hacia el tipo de activismo procesal y judicial que caracteriza el gerenciamiento y la conducción de procesos americanos de finales del siglo XX (CAPPELLETTI, GARTH, 1984, p. 252).

El aumento, fortalecimiento e intensificación del gerenciamiento judicial de casos se constatan en las reformas de los últimos años al sistema federal y también estadual en EEUU. Para ilustrar, en enero de 2017, la corte federal de San Francisco emitió una acordada que ordenaba la necesidad del uso de las reglas de gerenciamiento y que los tribunales lo aplicaran (MARCUS, 2017; SLOTNICK, 1983). Esta afirmación podría aplicarse a la mayoría de los sistemas procesales continentales. El tribunal es responsable de la dirección del proceso (STÜRNER, WENDELSTEIN, 2017). La extensión de los aspectos formales del procedimiento, como el poder dar inicio y conducción, dirigir su curso (\$136 (1) ZPO) y de cerrar la audiencia y proveer la decisión de la corte ( $\$ 136$ (4) ZPO), en Alemania, es una realidad positivamente valorada. El proceso civil en países que pertenecen a la familia legal romano-canónica es desconcentrado o bien incluye una audiencia concentrada en la principal inmediación judicial y rol central de audiencias lo más provechosas posibles, como en Alemania e Inglaterra (BETTINGER, 2016, p. 41-49, p. 69-77; ANDREWS, 2000, p. 464; GUINCHARD, 2015, p. 789-800, p. 843-848).

Como ha sido comentado por Fleck, la transparencia en la división de funciones, además de la independencia del poder judicial, es un factor decisivo sobre la operación de la conducción judicial como un todo en todas las instancias (FLECK, 2014, p. 11). Son relevantes desde una mirada horizontal al menos cuatro componentes importantes: (i) por un lado, la especialización de los tribunales (COMOGLIO, 2014, p. 16); (ii) por otro lado, la flexibilidad para adaptar la composición del tribunal y el procedimiento a la importancia y/o la complejidad del caso (único juez, tribunal colegiado, simplicidad del procedimiento); (iii) luego la incorporación de nuevas tecnologías y aplicación de inteligencia artificial tanto para mejora de la gestión administrativa como para la conducción de los procesos; (iv) finalmente un adecuado sistema multipuertas que coordine los métodos alternativos de solución de controversias con las vías adjudicativas (BADÓ, 2014, p. 27-58). 


\section{LA PREgUNTA SOBRE El DERECHO AL RECURSO Y EL ACCESO A LA APELACIÓN}

La toma de decisiones de la apelación tradicional en la mayoría de los casos se ve afectada por la sobrecarga de los tribunales de alzada. Al acelerarse el pronunciamiento de la sentencia en primera instancia por la adopción del modelo por audiencias, se eleva el número de sentencias susceptibles de apelación en menos tiempo, con un nivel jurisdiccional con menor cantidad de recursos humanos que el inferior. Acá se usa el término "apelación” en un sentido amplio para designar cualquier intento de tener la revisión de una corte superior sobre las investigaciones de hechos o de derecho de una corte inferior para obtener la corrección o eliminación de una decision judicial. Los países del Derecho Civil han tenido tradicionalmente una amplia gama de opciones de remedios contra las decisiones de las cortes (DONDI, ANSANELLI, COMOGLIO, 2015, p. 291). El método para desafiar las decisiones judiciales ante cortes de segunda instancia determina los arreglos necesarios para un trabajo de calidad eficaz y eficiente de aquellas.

Jolowicz (JOLOWICZ, 1999, p. 2-3) ha descrito una division de países de la Unión Europea en tres categorías: (i) países como Inglaterra y Suecia, donde todos los procedimientos de impugnación ante la primera instancia son llamados apelaciones; (ii) otros países donde una distinción se mantiene en mente entre un segundo nivel (apelación) y un tercer nivel (revisión), como Alemania y Austria; (iii) finalmente, países donde la distribución es en segundo nivel (apelación) y tercer nivel (casación), como España, Italia y Polonia. La administración y los procedimientos de apelación y de corte suprema son diferentes a los de una corte inferior (FERRAND, 1993; BIERSCHENK, 2015, p. 11-15). El corazón de la evaluación sobre la toma de decisiones judiciales en las cortes superiores es el filtro al acceso a la apelación con un criterio correcto de selección con la combinación de presentaciones escritas y orales (LANGBEIN, 2012, p. 522; BURBANK, SUBRIN, 2011, p. 399) para litigar y técnicas adicionales de administración de casos especiales de la segunda instancia que difieren de las empleadas por tribunales inferiores.

\section{I. LÍMITES Y DERECHO AL RECURSO}

Por un lado, con la voz "recurso" se refiere a un medio intra-procesal para objetar una decisión judicial, normalmente ante un tribunal o juez superior (VESCOVI, 1988, p. 336). Por otro, a todo mecanismo extraprocesal, en realidad de “acción” para la tutela de derechos. En los tratados internacionales hay una verdadera anfibología, tanto en relación a la voz "recurso" como en lo referido a "acción" de tutela de derechos fundamentales. De hecho, la Convención Americana sobre Derechos Humanos se refiere a una y otra en artículos distintos y también en la Convención Europea de Derechos Humanos en la versión en español y francés. Ahora bien, el derecho a recurso se vuelve relevante en el contexto de las reformas judiciales (HERZOG, KARLEN, 2014). En el Imperio Romano la apellatio cumplía una función. En efecto, si bien en principio los juzgadores eran seres humanos y, por lo tanto, el riesgo del error estaba siempre latente, la revisión de estas decisiones era siempre realizada por el 
Emperador, que tenía un origen divino y, en consecuencia, era infalible. La impugnación en Roma entonces cumplía una función de decisión última que era infalible (PRIORI POSADA, 2003, p. 414; VESCOVI, 1988, p. 18; SHAPIRO, 1979, p. 629).

Asimismo, no consagran expresamente un derecho al recurso en materias civiles los tratados internacionales sobre esta materia. En la mayoría de las Constituciones analizadas (Alemania, España, Francia, Italia, Suecia, Estados Unidos y Latinoamérica), en prácticamente ninguna existe consagrado expresamente un derecho a recurso en general, menos en materias civiles $^{2}$ (para España y su sistema restringido véase ESPARZA LEIBAR, 2007, p. 160-170). Italia y Suecia, asimismo, son países cuyas constituciones consagran, de algún modo, un derecho explícito a recurso aplicable también a materias civiles. Sin embargo, en ninguna se trata de un derecho a recurso en general (que incluya a las Cortes de Apelaciones) sino que en específico para acceder a la Corte Suprema. ${ }^{3}$

Con calidad, en este contexto, Couture, por ejemplo, en el proceso civil no incluía los recursos dentro del due process of law (COUTURE, 1979, p. 59 y ss.; Comp. ALSINA, 1961, p. 207). Sin embargo, una comprensión tal del derecho al recurso en tanto como derecho a ganar es objeto de críticas severas (LINDBLOM, 2000, p. 341). En otras palabras, el único que se beneficia de un derecho a recurso es aquel que logra revertir el fallo impugnado. ${ }^{4}$

Un aspecto adicional importante en las reformas introductorias de procesos por audiencia es el fortalecimiento de la primera instancia. Un cambio de paradigma es concentrar recursos e invertir en la primera instancia como señal de igualdad. Lindblom sostiene que desde el punto de vista de la igualdad todos los casos se benefician de los recursos invertidos en la

2 Dos casos excepcionales son Italia (derecho al recurso de casación) y, en Latinoamérica, Ecuador. En Latinoamérica la preocupación de los constituyentes pareciera haber sido la opuesta. En vez de consagrar un derecho a recurso para asegurar un sistema recursivo amplio, las disposiciones constitucionales que se encuentran buscan más bien restringir los recursos. En la lectura de Fix-Zamudio: "Son varias las Leyes Fundamentales Latinoamericanas que limitan expresamente las instancias a dos o tres, según estimen que el recurso de casación pueda dar lugar a una instancia o a una etapa diversa al proceso. En esta dirección podemos señalar los siguientes textos constitucionales: artículo 200 de la Carta Fundamental de Ecuador, artículo 245 de Guatemala; artículo 215 de Honduras y el artículo 232 de Nicaragua” (FIX-ZAMUDIO, 1974, p. 206).

3 En Italia, el artículo 111 de la Constitución consagra un derecho a la casación, que es exclusivamente conocida por la Corte Suprema italiana. En Suecia, el artículo primero del capítulo XI de la Constitución consagra que la Corte Suprema es la última instancia jurisdiccional. Sin embargo, a diferencia de Italia, ahí también se agrega que la legislación ordinaria puede establecer restricciones. Luego, si bien en Suecia está consagrado un derecho a recurrir ante la Corte Suprema, éste no constituye un límite a las reformas restrictivas del legislador.

4 Así, Pound resalta: "There is no-one who is not aware how frequently appeals are employed, and how necessary they are to correct the injustice or ignorance of judges" (POUND, 1941, p. 392). 
primera instancia, y sólo los casos meritorios y de probable reversibilidad impugnados se benefician del sistema de apelaciones, y no existe garantía de que la apelación será solamente utilizada en los casos correctos (esto es, contra una sentencia incorrecta) (LINDBLOM, 2000, p. 341). En el sistema continental, los jueces de primera instancia son normalmente nuevos en el trabajo, y la revisión de los casos mediante la apelación permite a los jueces de alzadamás experimentados-corregir los errores de aquellos y guiarlos en la profesión de juzgar (MARCUS, 2017; PETERSON, 1995, p. 41, p. 59; CHRISTENSEN, SZMER, 2012).

El dilema descrito se agrava si somos conscientes de qué tan injusta es una decisión incorrecta como una decisión tardía.

"Naturalmente existe todavía quien, de buena o de mala fe, piensa en la apelación y en el "doble grado de jurisdicción"como una importante garantía procesal, tal vez una garantía de libertad, incluso algo absoluto e insuprimible. Es indudable que esta concepción no resiste una crítica seria y desprejuiciada". Asimismo, Cappelletti ha expresado sus objeciones al principio de doble instancia señalando que "la apelación implica una perniciosa desvalorización del juicio de primer grado". (CAPPELLETTI, 1984, p. 252)

Adicionalmente, Couture ha expresado que "la privación de un recurso de apelación no pone en tela de juicio la efectividad de la tutela constitucional del proceso"(COUTURE, 1979, p. 158). Esta tesis ha sido ratificada por Vescovi, que ha señalado que "si el tribunal de segunda instancia es el que predominará y, por otra parte, es el que está mejor integrado (generalmente por la colegialidad y mayor versación y experiencia de sus miembros), ¿por qué no se suprime, entonces la primera instancia?" (VESCOVI, 1988, p. 13).

En el caso "Herrera Ulloa", resuelto por la Corte Interamericana de Derechos Humanos, se desprendería que el derecho de recurrir es una garantía primordial que se debe respetar en el marco del debido proceso legal, en aras de permitir que una sentencia adversa pueda ser revisada por "un juez o tribunal distinto y de superior jerarquía orgánica”, en realidad una exigencia de doble conforme en materia penal en interpretación integrada con el caso Mohamed vs. Argentina (CORTE INTERAMERICANA DE DERECHOS HUMANOS, 2012), pero no aplicable ni replicable a materia civil (SOSA, 2016). Hablar de doble instancia no equivaldría a hablar de doble juicio mediante apelación ni de revisión amplia. Incluso el derecho a recurrir por apelación es un derecho limitable y reglamentable cuando no eliminable en determinados casos (NÚÑ̃E, 2008, p. 199-223; CARRASCO, 2017, p. 443-469; NUÑEZ, CARRASCO, CORONADO, 2018; LOUTAYF, 1989, p. 62-63). ${ }^{\mathbf{5}}$

5 Finalmente la propia Corte Suprema de Justicia de la Nación Argentina, en autos "Recurso de Hecho deducido por Sociedad Anónima Organización Coordinadora Argentina en la causa Sociedad Anónima Organización Coordinadora 


\subsection{Modelos COMPARAdOS}

Adicionalmente a las adecuaciones horizontales de reformas hacia modelos por audiencia, es importante tener en cuenta las verticales, la interacción entre las cortes superiores e inferiores. El rol y los fines de la apelación en las cortes de apelación y el diálogo con las Cortes Supremas, el filtro al acceso, la carga de casos y el alcance de la revisión en la alzada y el procedimiento, tomando en cuenta que el número de jueces en los tribunales superiores no es el mismo que en las inferiores. La administración, dirección y gerenciamiento de procesos en la apelación es y debe ser diferente (POSNER, 2014, §22.18). Por ejemplo, respecto de la reforma alemana, el profesor Stürner explica que la reforma del 2001 talvez no sea el resultado de un gran trabajo de derecho comparado. Sin embargo, el memorándum del proyecto de ley de reforma se refiere a ejemplos de 'buena práctica' de Inglaterra, Austria, Suiza (Zurich), Francia e Italia para demostrar que los cambios previstos ya habían sido implementados en otras jurisdicciones. El mayor desarrollo de la reforma de 2001 fue la abolición de una apelación amplia. Se hicieron referencias al derecho austríaco y al inglés para demostrar que el foco debiese estar más bien en fortalecer los procedimientos de primera y limitar el acceso a la segunda instancia (STÜRNER, 2017).

Briggs en su reporte sostiene: "Rights of appeal are not necessarily to be equated with a right of a litigant to some theoretically correct outcome to their dispute... The perfect can be the enemy of the good, and theoretically perfect but very slow justice can be worse than timely, but slightly rough, justice for everyone." (BRIGGS, 2015, 9.30)

Un punto de vista opuesto al derecho ilimitado a la apelación como parte de un juicio justo es el que promueva los valores de la legitimación institucional, y el respeto por la dignidad individual y la decisión de la primera instancia (ROBERTSON, 2013, p. 1219). Así el pretendido estandar de revisión, para una amplia gama de resoluciones, sería un abuso de discreción. El resultado de la regla de tiempo, y el estandar de revisión de los jueces en Estados Unidos, ha sido bastante libre en contraste con el Continental-Europeo. Un ejemplo en California, aunque la Constitución de California establece cortes de apelación, no reconoce explícitamente un derecho de apelación en casos civiles o criminales (SALTZMAN, 2014, p. 95-104). También, en Inglaterra, no hay derecho a apelar; el apelante debe conseguir la venia "leave", o permiso de una corte superior, o de un juez de primera, para que el caso sea conocido en apelación (ANDREWS, 2014, p. 73-94).

Argentina s/Infracción a la Ley 22.802. causa $N^{\circ}$ 38.104", fallado con fecha 27-VI-2000 (Fallos 323:1787), doctrina reiterada en Fallos 325:2711 ("Butyl”), es decir, dicha garantía no tiene jerarquía constitucional en juicios civiles (Fallos 323:2357, voto del juez Petracchi), por lo que el debido proceso legal en causas como el sub lite no se afecta por la falta de doble instancia, salvo cuando las leyes específicamente lo establecen..." (Fallos 329:1180; abril, 2006)". 
En contraste, dentro de este horizonte de modelos restringidos como el proceso civil inglés ${ }^{6}$ o en modelos de renovación ex novo y amplios como el francés, pero con el requisito que la causa debe superar el monto de los 4000 euros para su admisibilidad por el inferior, quedando las causas por debajo de ese monto sometidas a otros recursos como el povoir de cassation (FERRAND, 2009; GALLET, 2010). ${ }^{\mathbf{7}}$

Alemania tiene una suma mínima de 1000 euros, pero con la posibilidad de apelar las causas por debajo de ese monto si coadyuvan al desenvolvimiento del derecho o su unificación (RIMMELSPACHER, 2016). La constitución alemana no garantiza el derecho a apelar (STÜRNER, 2017, p. 433-437). Esta posición está respaldada en consideración a que no hay una provisión expresa en la Ley Fundamental que confiera el derecho a una instancia ulterior, sin perjuicio de la garantía general de protección judicial contra cualquier acto de la autoridad pública, y las cortes de derecho son parte de la autoridad pública. Algunas posiciones usan este razonamiento para apoyar la idea de que, según ese principio, debe ser en contra de cualquier decisión de una corte. "Sin embargo, como esto podría llevar a una cadena infinita de apelaciones, toca al legislador establecer sus límites, tomando en cuenta otros valores constitucionales como el principio de finalidad. Las restricciones al acceso a la corte de apelación deben ser diseñadas siguiendo el principio de proporcionalidad” (STÜRNER, 2002, p. 79; ELLIOTT, THOMAS, 2012, p. 297). El tribunal de segunda instancia puede, no obstante, rechazar por inadmisible el recurso cuando la apelación no tiene posibilidad de éxito y el caso que no carece de importancia fundamental, no colabora al desarrollo del derecho ni a la unificación de la jurisprudencia (\$522 ZPO) que originalmente en el 2002 carecía de medio de impugnación contra la resolución, o que llevó luego a una reforma en el 2011 del sistema asegurando un recurso ante el superior por rechazo del recurso (RIMMELSPACHER, 2016; SAUERESSIG, 2008).

En Italia, Lupoi describe a las Cortes de Apelaciones como cortes de segunda instancia, de apelaciones contra decisiones de los tribunales inferiores. Tienen competencia funcional territorial sobre los Tribunales que están localizados dentro del circuito (en una escala regional o multi-provincial) (LUPOI, 2017, p. 1153-1178). "La Constitución Italiana no otorga el derecho constitucional de apelar en contra de un juicio de primera instancia. En otras palabras, el sistema constitucional italiano no otorga el derecho de jurisdicción de doble nivel. Tal adjudicación sobre los méritos, en doble nivel, sin embargo, está reconocido en el código de procedimiento civil (artículos 339 et seq)". Por cierto, con mucha crítica por parte de la doctrina, se incorporó el mismo modelo

$6 \quad$ Cfr. Rule 52.3 (1) CPR inglesas.

7 Ver igualmente Rapport Magandie I (2004) y II (2009). Efectivamente el doble grado jurisdiccional o doble instancia plena es visto como un derecho amparado por el art. 6 de la CEDH y 61 de la Constitución francesa, siendo la apelación una vía de "Réformation" como de "annulation" en los hechos y en el derecho, siendo posible plantear nuevas pretensiones y defensas como la producción amplia de prueba. 
alemán de filtro ex ante por el ad quem en el año 2012 (posibilidad de rechazo por éxito improbable del recurso por falta de importancia de la cuestión), pero sin los mecanismos impugnativos contra la decisión de admisibilidad, lo que es fuertemente criticado por la doctrina (FERRARI, 2014; CAPONI (a), 2012). Como argumentos esenciales, parten de que la justicia por metas de gestión y necesidad de ahorrar resulta finalmente atropellada con un fin meramente de descongestionamiento de la alzada (CAPONI (b), 2012).

\subsection{MAYOR EFICIENCIA Y LIMITACIÓN A LA APELACIÓN VS. MENOR EFICIENCIA Y AMPLITUD DE ACCESO A LA APELACIÓN}

Ahora bien, de cara al problema de restricción presupuestaria respecto del óptimo de eficiencia, el legislador no tiene una exigencia normativa que le imponga la carga de invertir una cantidad que supere su línea de presupuesto. Por tanto, si el punto óptimo de eficiencia se ubica por sobre tal línea, entonces el legislador no podrá satisfacer tal óptimo y tendrá que buscar una ponderación de los bienes en cuestión que se ubique en o bajo la línea de restricción presupuestaria (ATIENZA, MANERO, 2000, p. 147-156). Pues bien, en este caso: (i) cualquier restricción presupuestaria que impida alcanzar el punto de satisfacción del debido proceso respecto de la corrección del error judicial devendrá en irrelevante para tal garantía. Como consecuencia de ello, el legislador deberá adecuar su línea de presupuesto aumentando los recursos disponibles, al menos al nivel que le permita financiar el nivel de corrección del error judicial exigido por las consideraciones del debido proceso (ESPARZA LEIBAR, 2007, p. 160-170; SOSA, 2016); (ii) Existe una relación inversa de los costes sociales y privados. Es evidente que, no estando en peligro el debido proceso, el legislador no se encuentra impedido por ponderaciones que obstruyan o minimicen la inversión en la justicia donde mejor se satisface la visión del legislador auto-interesado (VARGAS, FUENTES, 2011).

Es admitido que la corrección del error por la falibilidad humana es en realidad apenas uno de los fundamentos de la existencia de la apelación (MALEM, 2008). Comúnmente el acto impugnativo se lleva a cabo por medio del recurso de apelación, el que tiene por objeto corregir las principales desviaciones que se observan en una sentencia (VOIGT, 2016, p. 183-208; HIERRO, 2002, p. 50-55). El juez, como todo ser humano, no está libre de cometer errores en la actividad jurisdiccional y, por lo tanto, es necesario conceder a las partes un mecanismo de reconsideración de eventuales fallas. Además, la posibilidad de impugnación sería un elemento del debido proceso (DALTON, 1985).

Cuando se desarrolla el paradigma "consecuencialista” de la decision judicial, considero que los magistrados judiciales no deben desentenderse de los efectos economicos y sociales que sus decisiones conllevan (LORENZETTI, 2006, p. 188, p. 219). De tal forma que, al interpretar la norma en un sentido o en otro, se deberan tener en cuenta las consecuencias que la decision tendra para los otros casos analogos. En tal sentido cabe recordar la enseñanza de Morello: "Compatibilizar la conjuncion criteriosa y en sinfonia del Derecho con la Economia" (MORELLO, 2005). 
Sostiene Shavell con corrección: "Having focused on error correction as a purpose of the appeals process, let me close with observations on its other possible functions. I have already discussed lawmaking as a purpose of appeal, noting the importance of lawmaking in fact but inquiring about the intrinsic need for the appeals process (rather than independent action of higher courts) to serve the lawmaking goal. A closely related function that the appeals process is often said to satisfy is harmonization of the law, namely, resolution of conflicts in the interpretation of the law among trial courts." (SHAVELL, 1995, p. 425)

La corrección del error es una visión minimalista de la apelación, pero por cierto la más cercana al interés de la parte perdedora. En realidad, la apelación persigue múltiples fines y, entre ellos, está otorgar legitimidad al proceso legal y también garantizar la unidad y uniformidad de la jurisprudencia. Parece claro, sin embargo, que cualquier necesidad de legitimar el proceso legal debe estar enraizada en la posibilidad de que el proceso pueda generar un error; de lo contrario, por definición, el proceso legal se considerará legítimo (SHAVELL, 1995, p. 425). Así en realidad se combina en la interrogante sobre el derecho a recurso no solo el acceso, sino también la extensión de impugnación que exige para verse satisfecho. La falibilidad no resulta ser suficiente fundamento en tanto también son humanos quienes integran la alzada, por un lado, la disidencia y la posibilidad de voto en mayoría y minoría son manifestaciones de ello (VARGAS, FUENTES, 2011, p. 343-355).

En este estudio, la opción de una apertura de la apelación sujeta a criterios objetivos discrecionales puede calificarse como una tercera vía frente a la inapelabilidad y la apelación ilimitada en su acceso. Considérase informada por una filosofía moral a la que se da el nombre de consecuencialismo calificado ya que es, en el criterio que se comparte, la que mejor combina el principio de proporcionalidad asociado a una guía de rendimiento sobre cómo operativizar la apertura de la puerta del recurso (MULLENDER, 2000). La corrección de errores y otros objetivos tiene un propósito privado y público. El sistema de apelación existe para satisfacer ambos intereses y propender a mantener el equilibrio entre ambas esferas (DE SAULLES, 2017). Acá se propone no un examen del superior de prognosis de éxito del recurso para poder arribar a un juicio ex ante de admisibilidad del mismo, sino uno ex post como parte de la decisión de mérito de la apelación que actúa como incentivo negativo en costas, y otras sanciones, como el aumento en sobre los límites de los honorarios del abogado vencedor (BRASIL, Art. 85, § 11, 2015).

\subsection{ANÁlisis ECONÓMICO DE LA APELACIÓN}

Siguiendo al AEDPR, los objetivos a procurarse incluyen dos tipos de costos a considerar: los que hacen al sistema de justicia en general en tanto costos administrativos y, por otro lado, la posibilidad de reducir los costos del error. Así puede hablarse de eficiencia cuando se contemplan ambos aspectos en equilibrio (WAGNER, 2009). Es con corrección un contrasentido cuando se afecta el debido proceso limitando irracionalmente el acceso a la justicia, siendo 
que se niega el debido proceso sob el pretexto del costo procesal, sin minimizar la posibilidad del error de una decisión. Aplicando dichos postulados, se llega a la conclusión de que se respeta el debido proceso, en materia de acceso a la justicia, si es el caso que un Tribunal se niega a dar una audiencia a un sujeto (derecho a ser oído) en el evento que el costo del respeto de la garantía sea mayor que la probabilidad del error si se niega la salvaguarda, multiplicado por la entidad de la pérdida si se materializa el error. Si se produce el caso contrario, entonces, debe concederse al ciudadano el derecho a ser oído por el órgano jurisdiccional (BRUNS, 2011; UNBERATH, 2007).

A partir del examen de lo formulado mencionado, que materializa las exigencias y propósitos del AEDPR, podríamos concluir que se posibilita una ponderación de los intereses involucrados en el resguardo del debido proceso, así como los criterios tendientes a la optimización de los costos sociales, por lo que la contradicción intuitiva antes indicada no sería tal. Evidentemente esta conclusión debe ser examinada a la luz de instituciones procesales, en particular donde estas exigencias concurran (PFLUGHAUPT, 2011). En relación a la apelación, algunos factores juegan recíprocamente y deben resolverse y para ello el AEDPR puede ser de gran ayuda. La limitación y el gerenciamiento adecuados del tiempo que insume eludir consecuencias dañosas para las partes cuando existe la incertidumbre de si lo decidido en primera instancia se mantiene o no (SHAVELL, 1995). Así el establecimiento de filtros de la apelación fijos combinados con elementos de discreción podría ser una opción cuando en definitiva el costo del recurso no compense sus beneficios.

Un primer mecanismo es la ejecución provisional de lo decidido o establecer la regla del cumplimiento inmediato (sin efecto suspensivo). Sin embargo, la parte victoriosa podría no optar por ejecutar frente al mínimo riesgo de revocación. La normalidad es que los litigantes son adversos al riesgo y consideran entre sus tácticas la posibilidad de una revocación con los gastos asociados a tener que restituir las cosas al estado ex ante. Este mecanismo es necesario pero no suficiente como incentivo para no interponer recursos caprichosos y meramente dilatorios (PICÓ Y JUNOT, 2013).

Un segundo mecanismo que parte de la visión de la administración de justicia como un servicio y que debe proveer externalidades positivas es focalizarse en la admisibilidad del recurso y prognosis de éxito del mismo (revocación) que, como se verá, combina eficiencia con el debido proceso. Tal mecanismo exige considerar límites o umbrales máximos y mínimos de error. Con el primero se tiende a la inadmisibilidad del recurso ya que los objetivos ya fueron correctamente logrados por el fallo de primera instancia. Con el segundo, por su lado, se incentiva la segunda instancia cuando es necesaria, evitándose las consecuencias negativas en algunos casos de instancia única aún cuando se inste al litigante propenso al riesgo con un examen ex post.

Sin embargo no resulta ajeno que se genera un mayor nivel de litigación donde se genera con mayor probabilidad la concurrencia de costos administrativos. Esto aún con posibilidad de ejecución provisional. Esto se explica ya que la mayoría de los litigantes se consideran 
con aversión el riesgo de la revocación. Recuérdese que el litigante no es neutral y considera riesgos y potencialidades de una segunda decisión. Consecuentemente el litigante instará a seguir litigando proporcionalmente como si fuera -y lo es no neutral-, aunque mucho menos aún, que una persona propensa (SHAVELL, 2006). El costo de la revocación aún con ejecución provisional es considerado un riesgo que sesga el uso del mecanismo sin sentencia confirmatoria del tribunal de apelación. Diferente, quizás, sería el panorama para el litigante ganancioso frente a una sentencia confirmatoria de segunda instancia y la eventualidad de un recurso extraordinario de su contraparte contra aquella.

La tercera vía que se propone para análisis es consagrar límites objetivos (monto) pero sumar que el tribunal inferior, con mayor o menor grado de discreción, pueda definir cuáles recursos serán finalmente conocidos y decididos. Así el tribunal de apelación con el beneficio social de la discrecionalidad para determinados casos tendría la facultad para considerar casos, no obstante evaluarlos ab initio como carentes objetivamente de resultado exitoso, darles tramitación y que la consecuencia de un caso no meritorio o abusivo se refleje en sanciones de diversas índoles en la sentencia de mérito del recurso, es decir, un control ex post. Una apelación debiera ser admitida si el beneficio social que generaría la apelación es superior al costo del procesamiento de la misma (SHAVELL, 1995). De esta forma no se prodiga una única instancia y además se genera una disminución al temor a la apelación. Con ello y el riesgo de la inadmisibilidad con los filtros adecuados se fortalece la decisión de primera instancia en un sistema de procesos por audiencia, pero sin eliminar la posibilidad de la apelación que contemple un filtro que trabaje con el límite o umbral mínimo de riesgo traducible en la decisión de mérito. El control es realizado por el inferior, pero en definitiva interesa el del superior para verificar si esa apelación en concreto satisface los límites o umbrales mínimos de error posible en los que haya incurrido la decisión impugnada. ${ }^{8}$ Téngase en cuenta que en Francia no hay examen de admisibilidad del superior basado en el éxito probable del recurso, lo que sí existe en Alemania.

8 Como datos estadísticos comparemos la apelación restringida alemana con la amplia francesa. El aumento de las apelaciones en Francia en el Tribunal inferior (Tribunaux de Grande Instance) subió desde el 12,6 (2004) al 14,5 (2008). Mientras que en Alemania fue del 14,2 (2005) al 15,5 (2009) en los OLG, mientras que en los LG disminuyó del 6,4 (2002) al 4,8 (2005) (STATISTISCHES BUNDESAMT 10, 2002 y 2005). Para un estudio del impacto de la reforma al ZPO alemán global puede verse el estudio HOMMERICH, PRÜTTING, EBERS, 2007. Entre el 2002 y el 2010 en Alemania la duración promedio en la apelación en los tribunales superiores de los estados (Oberlandesgericht-OLG) fue de 7,9 meses mientras que en los tribunales de los Estados (Landgerichten-LG) fue de 5,4 meses (STATISTISCHES BUNDESAMT 10, 2010, 2.1, Tabla 6.2) (STATISTISCHES BUNDESAMT 10, 2012, 2.1, Tabla 6.2). En el 2012 en Alemania en el OLG fue 8,7 y en el LG fue de 6,2 meses. En Francia, en la Cours d'appel fue de 14,3 meses, luego de la reforma del 2009 el promedio de duración de la apelación fue de 12,8 meses (www.justice.gouv.fr/statistique.html, acceso el 8/12/2018). 
Cuando se desarrolla el paradigma "consecuencialista" de la decision judicial consideramos que los magistrados judiciales no deben desentenderse de los efectos economicos y sociales que sus decisiones conllevan (SHAVELL, 1995). De tal forma que al interpretar la norma en un sentido o en otro, se deberan tener en cuenta las consecuencias que la decision tendrá para otros casos analogos.

Una apelación óptima, previstos sus objetivos y limitaciones, podría considerarse en la tercera vía que acá se propone en tanto: (i) El proceso de apelación es socialmente beneficioso y útil cuando hay un nivel de inversión en el proceso de apelación de tal manera que el costo de una apelación más el daño esperado por no revertir el error es menor que cierto daño por error, el último a ser lo que se sufriría en ausencia del proceso de apelación (FRYDMAN, 2008; VARGAS, FUENTES, 2011); (ii) Empleada la apelación con el criterio de la conducta del buen litigante, la parte perdedora convencida de que otra era la decisión posible apelará y siendo relevante para el sistema (no solo para el recurrente) el recurso prosperará. De la misma forma, quien perdió y se convence de la poca probabilidad de éxito o relevancia de su caso no recurrirá; (iii) La corrección y legitimidad de las decisiones de primera instancia son menores cuando se utiliza el proceso de apelación como una continuación de lo decidido por "el inferior" para que sea el "superior" quien haga verdaderamente justicia (SHAVELL, 2010). Hay muchas formas de seleccionar los casos que han de ser decididos por las cortes superiores como el manejo y fijación de tasas (FRYDMAN, 2008, p. 18 29). Incluso, en muchos países, esto no será un problema porque después de un incremento substancial de los precios de tasas judiciales estas son todavía una pequeña fracción de los costos de un caso (BÓKA, 2014, p. 141-161), incluso en casos no meritorios que son decididos poder aumentar sobre el límite los honorarios del abogado de la parte vencedora (BRASIL, Art. 85, § 1, 2015). A pesar de que la decisión de elevar la apelación no es discrecional de acuerdo a los requisitos legales recién mencionados, hay un considerable volumen de jurisprudencia que clarifica exactamente qué es una cuestión de significación (BIERSCHENK, 2015, p. 111-115; DONDI, ANSANELLI, COMOGLIO, 2015, p. 297). Los fundamentos para apoyar la apelación pueden ser una decisión fuerte desde un punto de vista legal, o desde la perspectiva fáctica, pero hay un ámbito limitado para revisar la investigación de los hechos. Una restricción al acceso podría ser evaluada hoy, desde la reforma del 2001, como un filtro justo y eficiente ex ante tanto en la primera instancia como en la segunda instancia (BIERSCHENK, 2015, p. 1-5).

Adopto así la opción de que una apelación sujeta a criterios objetivos y discrecionales en la primera instancia y con control discrecional ex post facto en la segunda puede bien calificarse como una tercera vía frente a la inapelabilidad y la apelación ilimitada. Considérase informada por una forma de filosofía moral a la que se da el nombre de consecuencialismo calificado ya que es, en el criterio que se comparte, la que mejor combina el principio de proporcionalidad asociado a una guía de rendimiento sobre cómo operativizar la apertura del recurso. La corrección de errores y otros objetivos tiene propósitos privados y públicos. El 
sistema de apelación existe para satisfacer ambos intereses y propender a mantener el equilibrio entre ambas esferas (DE SAULLES, 2017).

\section{Conducción de la APElación EN UN SISTEMA de PROCESOS POR AUdienCias}

Así es posible sostener que la técnica de conducción y alternativas de dirección de la apelación a partir de una primera instancia estructurada en procesos por audiencias en materia civil debe cambiar adoptando mecanismos de audiencia y participación de las partes en determinados supuestos, receptarse la ejecución provisional de las sentencias, introducirse los TIC e incentivarse también en este nivel medios autocompositivos, entre otras medidas. Teniendo un caso meritorio seleccionado adecuadamente y no solo por criterios de monto o cuantía en su admisibilidad, en alzada corresponde a que sea conocido y decidido (revisado y no como nuevo juicio) aplicando los recursos escasos ya mencionados para una sentencia justa de calidad.

Es conveniente y necesario que, al pensar en una reforma del proceso civil, el aporte debería centrarse en conciliar la oralidad y el doble grado con herramientas que permitan cumplir plenamente la función revisora (HITTERS, 1985, p. 71; ACOSTA, 1978, p. 181 y ss.). Así deben realizarse ajustes (i) que combinen un acceso selectivo en la calidad, relevancia e importancia no solo pecuniariamente sino con cláusulas selectivas en caso de no satisfacerse el monto mínimo y ser materia donde se precisa por su importancia para el desarrollo del derecho de un pronunciamiento de la alzada; (ii) una adecuación y sustanciación de la apelación que permita una audiencia de vista de la causa en el caso donde se pueda producir prueba en la alzada, la inmediación y el contacto con las partes es un valor que debiera también considerarse en la alzada; (iii) deben incorporarse nuevas tecnologías que permitan el acceso al registro de imagen y sonido en primera instancia a los efectos de la revisión, pero también el expediente digital que reduzca los tiempos de elevación y devolución del expediente que, siendo digital, eliminaría muchos inconvenientes; (iv) uso e invitación a los ADR también en segunda instancia; (v) instauración de incentivos negativos o de imposición de razonabilidad costo-beneficio mediante la ejecución provisional o inmediata de la sentencia (SHAVELL, 2006).

Hay casos donde la apelación podría eliminarse y es aceptable una única instancia en materia civil y comercial. Esto a partir de la diferencia entre discurso de fundamentacion (o justificacion) y discurso de aplicacion o adecuacion, como formas discursivas complementarias (HABERMAS, 1992, p. 349 y ss.). Es aqui donde el discurso de aplicacion o adecuacion que solo pueden y tienen legitimidad para hacerlo los jueces que intervinieron en el proceso por audiencias en primera instancia es respetable: este discurso se refiere a la correccion de la decision juridica motivada en inmediación, en la cual hay que establecer si la norma prima facie aplicable es adecuada a una situacion determinada, para lo que es necesario tener en cuenta todos los datos que caracterizan a esa situacion, es decir, la situacion 
de aplicacion (GÜNTHER, 1988; BUNG, 2003; TARUFFO, 1975; DE ASÍS, 2005, p. 77 y ss.; TROCKER, VARANO, 2005).

Parece ser igualmente sensible que los jueces deban dedicar menos de su atención a los casos de lo que pensaron que podría ser correcto, sin un tratamiento judicial completo (REINHARDT, 1993, p. 52-53). Reducir el número de casos, para las cortes de alzada, es un desafío importante de políticas públicas: (i) las cortes de apelaciones y las superiores, o las cortes supremas, están luchando, en muchos países, con una gran carga de casos y con presupuestos que no se han adaptado para asegurar la reducción de los tiempos de espera; (ii) al mismo tiempo, parece haber muchos casos de poco mérito, motivados principalmente por tácticas de retardo, habiendo simultaneamente casos meritorios, y otros de interés público, que necesitan una pronta atención judicial (KODEK, 2014, p. 35-52; POLINSKY, RUBINFELD, 1993).

El case managment en los tribunales de alzada debiesen enfocarse en su responsabilidad para alcanzar la decisión correcta, o preferible. La corte es un participante activo en el proceso de revisión, asegurando que cada aplicación sea gestionada apropiadamente y que proceda en un tiempo razonable (COOPER, BERMAN, 2000; RICHMAN, REYNOLDS, 1996, p. 273; FISS, 1983, p. 1442, p. 1446). A pesar de su importancia, las decisiones de apelación pueden fácilmente distorsionar la percepción sobre el sistema legal (EISENBERG, 2004, p. 659-688; ROBERTSON, 2013, p. 1219).

¿Cómo podrían las cortes razonablemente maximizar la corrección de errores y el desarrollo del derecho al mismo tiempo? Si la corrección de errores y el desarrollo del derecho pudiesen ser fácilmente medidos y cuantificados, uno podría crear una función que aspirara a maximizar una combinación de ambas. Desafortunadamente, sin embargo, ambos, la corrección de errores y el desarrollo del derecho, desafían las mediciones precisas (LEVY, 2013). Hay una tensión entre "menos apelación, más eficiencia”, y "más apelación, menos eficiencia". Para simplificar la tarea, uno puede desagregar las dos variables y considerar maximizarlas cada una a la vez (REHNQUIST, 1993, p. 1, p. 3). Un mecanismo importante es el de desarrollar un criterio adecuado de selección judicial para la revisión de casos: una combinación de limitaciones formales, con discreción para controlar, es su propia agenda (HERZOG, KARLEN, 2014, p. 54; FROST, 2008).

El gerenciamiento de casos en la apelación ha sido normalmente pasado por alto por la doctrina. Las cortes de apelaciones necesitan un gerenciamiento de casos especial, con al menos los siguientes puntos: (i) si por casualidad un caso recibirá argumentos orales o será decido solamente en forma escrita (TIDMARSH, 2016, p. 475-486); (ii) si acaso sus resoluciones serán escritas por los jueces y sus ayudantes judiciales o por abogados funcionarios; (iii) si acaso se resolverá por un fallo público o no público y cómo se realizarán las deliberaciones y las votaciones, los roles de las mayorías y minorías (WALLACE, 2005, p. 187, p. 192; HAWORTH, 1973; MARTINEU, 1986; SCHIAVONI, 2002); (iv) la dinámica generada por el juego entre la agenda y las prioridades de la corte. Un punto de vista adicional es el uso de mediación en las cámaras de apelaciones, que tiene una sorprendente pequeña atención 
académica. Mientras que la mediación de juicio ha sido objeto de vasta y sostenida literatura, enfocada en cómo la mediación se detracta del rol público de la adjudicación, la misma ha sido poco explorada a nivel de la apelación (JORDAN, 2007; para el uso de la conciliación y mediación a nivel de los tribunales de apelación en China puede verse CHAN, 2017, p. 167-170).

Las prioridades del tribunal de apelación son, de hecho, una combinación de estos valores, y otros, incluyendo justicia, legitimidad, eficiencia, interés público, por normar algunos. Es un problema constante determinar cuáles prácticas serán mejor efectuadas (LEVY, 2011 , p. 27). Varios factores afectan las tasas de apelación: incentivos a la litigación y acuerdos, la diferencia entre los litigantes y un pronóstico diferenciado respecto del éxito de la apelación (EISENBERG, FARBER, 2013, p. 73-109). Un apropiado sistema de filtro tiene un rol cualitativo y cuantitativo, y un propósito (DRAGO, FAUVARQUE COSSON, GORÉ, 2015, p. 1-20).

En este sentido, la propuesta de las Bases para la Reforma 2020 en Argentina dan una luz de lo deseado y como quizás para ello haya que tener en cuenta lo detallado anteriormente. La celeridad y prohibición de reenvío es un adecuado mecanismo de gerenciamiento en la alzada. Además, lo principal a indagar en esta investigación es incorporar el logro "de la inmediación del tribunal de alzada con las partes y con el material del litigio a través de la petición de las mismas para exponer oralmente y en audiencia los motivos de agravios y lo la contestación de los mismos, como disponer que toda la prueba que deba ser producida en la cámara se reciba de modo oral en audiencia (explicación de peritos, declaración de testigos o partes). Ello sin perjuicio de recibir la filmación de todo lo actuado en las audiencias de primera instancia”.

Esto resulta viable desde que debe recordarse que la apelación no es un nuevo juicio. El modelo de apelación es una versión intermedia entre el más restringido y el más amplio (PERROT, 1979, p. 1986; PRIETO-CASTRO, 1964, p. 351; HITTERS, 1985, p. 503). En este sistema, solamente se puede rendir la misma prueba que ya se rindió en primera instancia y no se pueden formular nuevas pretensiones (CARNELUTTI, 1944, p. 722). El cambio a un procedimiento destacadamente oral o mejor dicho "por audiencias" produce la necesidad de repensar el sistema del recurso de apelación (LOUTAYF, 1989, p. 410; IBAÑNZ, 1969, p. 141, p. 143).

\section{CONCLUSIONES}

1. La atención que los tribunales de apelación (al igual que los jueces de primera instancia civil) pueden prestar a los casos que conocen se ha convertido en un "recurso escaso".

2. Soy de la opinión de acuerdo a lo analizado que deben existir filtros objetivos en primera instancia, como la cuantía de la disputa, pero sumar a ellos la posibilidad discresional de admitir 
la apelación para los supuestos por debajo del tope cuando: la importancia de lo discutido para desarrollo del derecho o bien para la unificación de la jurisprudencia. Allí un control ex ante se justifica y permite un sano descongestionamiento de la segunda instancia y a su vez no deja sin tutela a casos que por sus características lo ameritan. Por el contrario, en la segunda instancia creo que los filtros ex ante fundados especialmente en la prognosis de éxito del recurso o importancia de la causa no son adecuados y funciona mejor un control ex post, con tramitación de la apelación en la audiencia de vista del recurso contra sentencias definitivas que permitan incluso actividad probatoria y con el adecuado gerenciamiento y conducción con los aditamentos de discresionalidad propios de un tribunal colegiado. La sanción ex post para el recurso innecesario puede traducirse en sanciones de la más variada gama contra el que recurrió y objetivamente estaba destinado a perder el recurso.

3. La administración de casos en cámaras de apelación ha sido normalmente pasada por alto. Las cortes de apelaciones necesitan una "administración de casos" especial con la incorporación en algunos casos de la vista del recurso para dar oportunidad a las partes de ser oídas en segunda instancia.

\section{AGRADECIMIENTOS}

El autor agradece el apoyo financiero de la Universidad Católica del Norte (Chile) y de la Universidad de San Pablo-T (Tucumán, Argentina).

\section{REFERENCIAS}

ACOSTA, José. Agravio irreparable. Buenos Aires: Ediar, 1978.

ALSINA, Hugo. Tratado teórico práctico de derecho procesal civil y comercial. Tomo IV, $2^{\mathrm{a}}$ ed. Buenos Aires: Ediar, 1961.

ANDREWS, Neil. English Case Management System (Report England), London: Inédito, 2017.

ANDREWS, Neil. A New System of Civil Appeals and a New Set of Problems, Cambridge Law Journal, Vol. 59, n. 3, p. 464-466, 2000. 
ANDREWS, Neil. Restriction On Appeal in English Law, in Uzelac, A.; van Rhee, R. (Eds.) Nobody's Perfect: Comparative Essays on Appeals and Other Means of Recourse, Cambridge: Intersentia, p. 73-94, 2014.

ATIENZA RODRÍGUEZ, Manuel; MANERO, Javier. Rules and principles revisited, Associations Journal for Legal and Social Theory, Vol. 4, n. 1, p. 147-156, 2000.

BADÓ, Attila. "Fair" Selection of Judges in a Modern Democracy, in Badó (Ed.) Fair Trial and Judicial Independence, Dordrecht: Springer, p. 27-58, 2014.

BALDWIN, John. Pre-Trial Justice. London: Blackwell, 1985.

BASES PARA LA REFORMA ENARGENTINA (2017). https: / /www.justicia2020.gob.ar/wp-content/uploads/ 2017/06/Bases-para-la-Reforma-de-la-Justicia-Civil-y-Comercial.pdf. (Visitado 5/5/2018).

BETTINGER, Nicole. Prozessmodelle im Zivilverfahrensrecht: Erfolg des Hauptverhandlungsmodells. Tübingen: Siebeck, 2016.

BIERSCHENK, Lars. Die zweite Instanz im Detuschen und französischen Zivilverfahren.Tübingen: Siebeck, 2015.

BÓKA, János. “To Delay Justice is Injustice”: A Comparative Analysis of (Un) Reasonable Delay, in Badó (Ed.) Fair Trial and Judicial Independence, Dordrecht: Springer, p. 141-161, 2014.

BRASIL. PRESIDÊNCIA DA REPÚBLICA. Lei n. 13.105, de 16 de março de 2015. http: / /www.planalto. gov.br/ccivil_03/_ato2015-2018/2015/lei/113105.htm.(Visitado 20/8/2019).

BRIGGS, Michael, Lord Justice. Civil Courts Structure Review: Interim Report, Judiciary of England and Wales, London, 2015.

BRUNS, Alexander. Der Zivilprozess zwischen Rechtsschutzgewärsleistung und Effizienz, Zeitschrift für Zivilprozesst, Vol. 124, n. 1, p. 29-44, 2011.

BUNG, Jochen. Subsumtion und Interpretation. Nomos: Baden-Baden, 2003.

BURBANK, Stephen; SUBRIN, Stephen. Litigation and Democracy: Restoring a Realistic Prospect of Trial, Harvard Civil Rights-Civil Liberties Law Review, Vol. 46, p. 399-414, 2011.

CAMERON, Charles M.; KORNHAUSER, Lewis. Decision Rules in a Judicial Hierarchy, Journal of Institutional and Theoretical Economics, Vol. 161, n. 2, p. 264-292, 2005. 
CAPONI, Remo (a). La riforma dei mezzi di impugnazione, Rivista Trimestrale di Diritto e Procedura Xivile, Vol. 66, n. 4, p. 1153-1178, 2012.

CAPONI, Remo (b). Contro il nuovo filtro in appello e per un filtro di cassazione nel processo civile, Giurisprudenza constituzionale, Vol. 57, n. 2, p. 1539-1556, 2012.

CAPPELLETTI, Mauro. Proceso, Ideologías, Sociedad. Buenos Aires: Ediciones Jurídicas Europa-América, 1974.

CAPPELlETTI, Mauro; GARTH, Bryan. A Comparative Conclusion, in Cappelletti (Ed.) Ordinary Proceedings in First Instance-International Encyclopedia of Comparative Law, Tübingen: Mohr, 1984.

CARNELUTTI, Francesco. Sistema de Derecho Procesal Civil. Buenos Aires: UTHEA, 1944.

CARRASCO, Nicolás. La eficiencia procesal y el debido proceso, Revista de Derecho Privado, n. 32, p. 443 $469,2017$.

CARRINGTON, Paul D. The Function of the Civil Appeal: A Late-Century View, South Carolina Law Review, Vol. 38, p. 411-435, 1987.

CAUTHEN, James; LATZER, Barry. Why so long? Explaining processing time in capital appeals, The Justice System Journal, Vol. 29, n. 3, p. 298-312, 2008.

CHAN, Peter. Mediation in Contemporary Chinese Civil Justice: A Proceduralist Diachronic Perspective. Leiden; Boston: Brill - Nijhoff, 2017.

CHAYES, Abram. The Role of the Judge in Public Law Litigation, Harvard Law Review, Vol. 89, n. 7, p. 1281-1316, 1976.

CHRISTENSEN, Robert K.; SZMER, John. Examining the efficiency of the U.S. courts of appeals: Pathologies and prescriptions, International Review of Law and Economics, Vol. 32, p. 30-37, 2012.

COMOGLIO, Paolo. II giudice specializzato in materia di impresa. Torino: Giappichelli, 2014.

COOPER, Jeffrey O.; BERMAN, Douglas A. Passive Virtues and Casual Vices in the Federal Courts of Appeals, Brooklyn Law Review, Vol. 66, p. 685-754, 2000.

CORTE INTERAMERICANA DE DERECHOS HUMANOS. Sentencia 23 de Noviembre de 2012, Costa Rica, San Jose de Costa Rica. 
COUTURE, Eduardo. Estudios de Derecho procesal civil. vol. I - La constitución y el proceso civil. $3^{\mathrm{a}}$ ed. Buenos Aires: Depalma, 1979.

DALTON, Harlon. Taking the Right to Appeal (More or Less) Seriously, Yale Law Journal, Vol. 95, p. 62 107, 1985.

DE ASÍS ROIG, Rafael. El Juez y la motivacion en el Derecho. Madrid: Dykinson, 2005.

DE SAULlES, Dominic. Process Costs and Error Costs: The Reform of Civil Appeals in AngloAmerican Perspective, Athens Journal of Law, p. 179-200, 2017.

DONDI, Angelo; ANSANELLI, Vicenzo; COMOGLIO, Paolo. Processsi Civili in Evoluzione. Una Prospettiva Comparata. Milano: Giuffrè, 2015.

DRAGO, Guillaume; FAUVARQUE COSSON, Bénédicte; GORÉ, Marie (Eds.) L'acces au juge de cassation. Societe de Legislation Comparee, 2015.

DRAHOZAL, Christopher. Judicial Incentives and the Appeals Process, Southern Methodist University Law Review, Vol. 51, n. 3, p. 498-499, 1998.

EISENBERG, Theodore; HEISE, Michael. Plaintiphobia in State Courts? An Empirical Study of State Court Trials on Appeal, Journal of Legal Studies, Vol. 38, p. 121-155, 2008.

EISENBERG, Theodore. Appeal Rates and Outcomes in Tried and Nontried Cases: Further Exploration of Anti-Plaintiff Appellate Outcomes, Journal of Empirical Legal Studies, Vol. 1, p. 659-688, 2004.

EISENBERG, Theodore; FARBER, Henry S. Why Do Plaintiffs Lose Appeals? Biased Trial Courts, Litigious Losers, or Low TrialWin Rates? American Law and Economic Review, Vol. 15, p. 73-109, 2013.

ELLIOTT, Mark; THOMAS, Robert. Tribunal Justice and Proportionate Dispute Resolution, Cambridge Law Journal, Vol. 71, p. 297-324, 2012.

ESPARZA LEIBAR, Inaki. La instancia de apelacion civil: Estudio comparativo entre Espana y Alemania. Valencia:Tirant lo Blanch, 2007.

FERRAND, Fréderique. Cassation francaise et révision allemande: essai sur le controle exerce en matiere civile par la Cour de cassation francaise et par la Cour federale de justice de la Republique federale d'Allemagne. Paris: PUF, 1993. 
FERRAND, Fréderique. L'évolution récente de l'appel en droit français, Zeitschrift für Ziilprozessrecht International, p. 43-82, 2009.

FERRARI, Francesca. The Recent Amendments to the Italian Appeal System, in Uzelac A.; van Rhee, R. (Ed.) Nobody's Perfect: Comparative Essays on Appeals and Other Means of Recourse, Cambridge: Intersentia, p. 259-272, 2014.

FISS, Owen. The Bureaucratization of the Judiciary, Yale Law Journal, Vol. 92, p. 1442-1468, 1983.

FIX-ZAMUDIO, Héctor. Constitución y proceso civil en Latinoamérica. México: UNAM, 1974.

FLECK, Zoltán. A Comparative Analysis of Judicial Power, Organisational Issues in Judicial in Judicature and the Administration of Courts, in Badó (Ed.) Fair Trial and Judicial Independence, Dordrecht: Springer, 2014.

FROST, Amanda. Overvaluing Uniformity, Virginia Law Review, Vol. 94, n. 7, p. 1567-1639, 2008.

FRYDMAN, Benoît. L'evolution des criteres et des modes de controle de la qualite des decisions de justice, in Mbongo, P. (Ed.) La qualité de la decision de justice, Paris: Ed. Conseil del'Europe, p. 18-29, 2008.

GALLET, Jean-Louis. La procédure civile devant la Court d’appel. 2ª ed. Paris: Litec, 2010.

GRIMM, Dieter, Bedingungen demokratischer Rechtsetzung, Die Offentlichkeit der Vernunft der Offentlichkeit. Festschrift fur Jurgen Habermas (L.Wingert / K. Gunther), SuhrkampVerlag, Frankfurt, p. 489 y ss, 2001.

GUINCHARD, Serge. Les garanties institutionelles du droit à un bon judge, in Droit Processuel-Droit fondamentaux du procès, $8^{\text {a }}$ ed., Paris, p. 789-800, p. 843-848, 2015.

GÜNTHER, Klauss. Der Sinn fur Angemessenheit. Anwendungsdiskurse, in Moral und Recht. Frankfurt: Suhrkamp Verlag, 1988.

HABERMAS, Jürgen. Faktizitat und Geltung. Frankfurt: Suhrkamp Verlag, 1992.

HAWORTH, Charles. Screening and Summary Procedures in the United States Courts of Appeals, WASH. U. L.Q., 257, 1973.

HERZOG, Peter; KARLEN, Delmar. Attacks on Judicial Decisions, in Cappelletti, Mauro (Ed.) International Encyclopedia of Comparative Law, Vol. 16, Leiden \& Boston: Martinus Nijhoff Publishers, 2014.

HIERRO, Liborio. Justicia, igualdad y eficiencia. Madrid: Centro de Estudios Políticos y Constitucionales, 2002. 
HITTERS, Juan Carlos. Técnica de los Recursos Ordinarios, 1ª ed. Platense, La Plata, 1985.

HITTERS, Juan Carlos. Técnica de los Recursos Ordinarios. La Plata: Platense, 1988.

HOMMERICH, Christoph; PRÜTTING, Hanns (Coord.). Rechtstatsächliche Untersuchung zu den Auswirkungen der Reform des Zivilprozessrechts auf die gerichtliche Praxis - Evaluation ZPO-Reform (Rechtstatsachenforschung). München: Beck, 2006.

HOMMERICH, Christoph; PRÜTTING, Hanns; EBERS, Thomas. Rechtstatsächliche Untersuchung Evaluation ZPO-Reform, 2007.

IBAÑEZ FROCHAM, Manuel. Tratado de los Recursos en el Proceso Civil. Buenos Aires: La Ley, 1969.

JOLOWICZ, Antony; Van RHEE, Cornelius. Recourse Against Judgement in the European Union. The Hague: Kluwer Law International, 1999.

JORDAN, Samuel P. Early Panel Announcement, Settlement and Adjudication, B. Y.U. Law Review, Vol. 55, 2007.

KODEK, Georg. Apellate Proceedings in Civil Cases. Traditional Remedies in Light of Contemporary Problems, in Uzelac, A.; Van Rhee, C. H. (Eds.) Nobody's Perfect: Comparative Essays on Appeals and Other Means of Recourse, Antwerp: Intersentia, p. 35-52, 2014.

KOURLIS, Rebecca Love; KAUFFMAN, Brittany K.T. Rule Reform, Case Management, and Culture Change: Making the Case for Real and Lasting Reform, KAN.J.L. \& PUB.POL'Y, p. 494-517, 2015.

KORNHAUSER, Lewis A. Appeal and Supreme Courts, in Encyclopedia of Law and Economics, General Editors Boudewijn Bouckaert, Gerrit De Geest, Volume V.The Economics of Crime and Litigation 7200, Cheltenham, Edward Elgar, p. 45-62, 2000.

LANGBEIN, John H. The Disappearance of Civil Trial in the United States, Yale Law Journal, Vol. 122, p. 522, 2012.

LANGBROEK, Philip. From the Managing Editor: Court Administration in Europe - Management in a Different Context. International Journal for Court Administration, 8 (3), p. 1-2, 2017.

LANGER, Maximo. The Rise of Managerial Judging in International Criminal Law, Research Paper 05 16, University of California, Los Angeles, 2005. Checkable at http: / / ssrn.com/abstract $=765744$ (Visitado 5-6-2018). 
LEVY, Marin K. The Mechanics of Federal Appeals: Uniformity and Case Management in the Circuit Courts, Duke Law Journal, Vol. 61, p. 315, p. 327, 2011.

LEVY, Marin K. Judicial Attention as a Scarce Resource: A Preliminary Defense of How Judges Allocate Time Across Cases in the Federal Courts of Appeals, The GeorgeWashington Law Review, Vol. 81, p. 401, 2013.

LINDBLOM, Henrik. The role of Supreme Courts in Scandinavia, Scandinavian Studies in Law, Vol. 39, p. 341, 2000.

LORENZETTI, Ricardo. Teoria de la decision judicial. Fundamentos de derecho. Buenos Aires: RubinzalCulzoni, 2006.

LOUTAYF RANEA, Roberto. El recurso ordinario de apelación en el proceso civil. Tomo 1, Buenos Aires: Editorial Astrea de Alfredo y Ricardo Depalma, 1989.

LUPOI, Michele Angelo. Appellate procedures in Italy, Counsil of Europe, 2017. Inédito.

MCCLUSKEY, Martha T; PASQUALE, Frank; TAUB, Jennifer. Law and Economics: Contemporary Approaches, Yale Law \& Policy Review, Vol. 35, n. 1, p. 297-318, 2016.

MALEM SENA, Fernando. El error judicial y la formacion de los jueces. Barcelona: Gedisa, 2008.

MARCUS, Richard. Controlling the cowboy lawyers: how American judges are managing American cases, National Report USA. San Francisco: Inédito, 2017.

MARCUS, Richard. Reining in the American Lawyer: The New Role of American Judges, Hastings International \& Comparative Law Review, Vol. 27, n. 3, p. 3, 2003.

MARTINEU, Robert J. The Value of Appellate Oral Argument: A Challenge to the Conventional Wisdom, Iowa Law Review, Vol. 72, p. 1, 1986.

MORELLO, Augusto Mario. El proceso judicial versus la economia, LexisNexis (hoy AbeledoPerrot on line) del 17-10-2005 (Visitado 5-5-2018).

MULLENDER, Richard. Theorizing the Third Way: Qualified Consequentialism, the Proportionality Principle, and the New Social Democracy, Journal of Law and Society, Vol. 27, n. 4, p. 493-516, 2000.

NOBLES, Richard; SCHIFF, David. The Right to Appeal and Workable Systems of Justice, Modern Law Review, Vol. 65, p. 676, 2002. 
NÚÑEZ OJEDA, Raúl. El sistema de recursos procesales en el ámbito civil en un estado democrático deliberativo, Ius et Praxis, Vol. 14, p. 199-223, 2008.

NÚÑEZ OJEDA, Raúl; CARRASCO DELGADO, Nicolás; CORONADO ATENAS, Martín. Compatibilidad entre debido proceso y eficiencia: su aplicación al régimen de apelación en el proceso civil chileno, Revista de Derecho, Vol. 31, n. 2, p. 211-235, oct., 2018.

PERROT, Roger. Le príncipe du doble degré de juridiction et son evolution en droit judiciarie privé français, in Studi in onore di Enrico Tullio Liebman, Cedam: Milán, Vol. III, p. 1986, 1979.

PETERSON, Todd. Restoring Structural Checks on Judicial Power in the Era of Managerial Judging, University California Davis Law Review, Vol. 29, n. 41, p. 59, 1995.

PFLUGHAUPT, Mathias. Prozessöconomie. Tübingen: Ed. Mohr Siebeck, 2011.

PICÓY JUNOT, Joan. La ejecución provisional de las sentencias de primera instancia estudio del conflicto entre los derechos al recurso y a la ejecución, Revista del Instituto Colombiano de Derecho Procesal, Vol. 39, n. 39, p. 63-78, 2013.

POLINSKY, Mitchell; RUBINFELD, Daniel L. Sanctioning Frivolous Suits: An Economic Analysis, The Geogetown Law Journal, Vol. 82, p. 397, 1993.

PORAT, Ariel. Private Production of Public Goods: Liability for Unrequested Benefits, The Michigan Law Review Association, Vol. 108, n. 2, p. 189-227, 2009.

POSNER, Richard A. Economics Analysis of Law. New York: Wolters Kluwer Law, 2014.

POSNER, Richard A. The Role of the Judge in the Twenty-First Century, Boston University Law Review, Vol. 86, p. 1049-1068, 2006.

POUND, Roscoe. Appellate Procedure in Civil Cases. Boston: Brown \& Company, 1941.

PRIETO-CASTRO FERRANDIZ, Leonardo. Limitaciones de la apelación, in Trabajos y orientaciones de Derecho Procesal Civil, Madrid:Tecnos, 1964.

PRIORI POSADA, Giovani. Reflexiones en torno al doble grado de jurisdicción, Advocatus $N^{\circ}$ 9, Revista editada por alumnos de la Facultad de Derecho de la Universidad de Lima, p. 405-422, 2003.

REHNQUIST, William. Seen in a Glass Darkly: The Future of the Federal Courts, Wisconsin Law Review, 
n. 1, p. 1-12, 1993.

REINHARDT, Stephen. A Plea to Save the Federal Courts: Too Few Judges, Too Many Cases, American Bar Association Journal, Vol. 79, n. 1, p. 52-54, 1993.

RICHMAN, William M.; REYNOLDS, William L. Elitism, Expediency, and the New Certiorari: Requiem for the Learned HandTradition, Cornell Law Review, Vol. 81, p. 273, 1996.

RIMMELSPACHER, Bruno. in Krüger, W. / Rauscher, T. (Coord.). Münchener Kommentar Zivilprozessordnung, München: Beck, §§ 511, 522.

ROBERTSON, Cassandra B. The Right to an Appeal, North Carolina Law Review, Vol. 91, p. 1219, 2013.

SALTZMAN, Andrea. Appellate review in California: limits on the right to recourse, in Uzelac A.; Van Rhee, R. (Eds.) Nobody's Perfect: Comparative Essays on Appeals and Other Means of Recourse, Cambridge: Intersentia, p. 95-104, 2014.

SAUERESSIG, Christian. Das System der Rechtsmittel nach dem Zivilprozessreformgesetz. Kön: Heymman, 2008.

SHAPIRO, Martin. Appeal, Law and Sociology Review, Vol. 14, p. 629, 1979.

SHAVELL, Steven. On the Design of the Appeal Process: The Optimal Use of Discretionary Review versus Direct Appeal, The Journal of Legal Studies, Vol. 29, p. 63, 2010.

SHAVELL, Steven. The Appeals Process and Adjudicator Incentives, The Journal of Legal Studies, Vol. 35, p. $1,2006$.

SHAVELL, Steven. The Appeals Process as a Means of Error Correction, The Journal of Legal Studies, Vol. 24, n. 2, p. 379-426, 1995.

SCHIAVONI, Johanna. Who's Afraid of Precedent? The Debate Over the Precedential Value of Unpublished Opinions, UCLA Law Review, Vol. 49, p. 1859, 2002.

SLOTNICK, Elliot. Federal trial and appellate judges: How do they differ? Western Political Quarterly, Vol. 36, n. 4 , p. 570-578, 1983.

SOSA, Toribio. Doble instancia vs. doble conforme, El Derecho, 267, mayo, 2016. 
STATISTISCHES BUNDESAMT (Estadísticas de la Agencia Federal) 10, 2002 y 2005. https: / www.destatis. de/GPStatistik/servlets/MCRFileNodeServlet/DEHeft_derivate_00011392/0100001087001.pdf;js essionid=AB65518E9820410205B24006F926131D. (Visitado 20/8/2019).

STATISTISCHES BUNDESAMT (Estadísticas de la Agencia Federal) 10, 2010. https: / /www.destatis.de / GPStatistik/servlets/MCRFileNodeServlet/DEHeft_derivate_00011392/0100001087001.pdf;jsessio nid=AB65518E9820410205B24006F926131D. (Visitado 20/8/2019).

STATISTISCHES BUNDESAMT (Estadísticas de la Agencia Federal, 10, 2012. https: / /www.destatis.de/ GPStatistik/servlets/MCRFileNodeServlet/DEHeft_derivate_00011392/0100001087001.pdf;jsessio nid=AB65518E9820410205B24006F926131D. (Visitado 20/08/19).

STÜRNER, Michael. Die Anfechtung von Zivilurteilen. München: C.H. Beck, 2002.

STÜRNER, Michael; Wendelstein, Christoph. Case Management in Civil Proceedings in Germany, National Report. Konstanz: Inédito, 2017.

STÜRNER, Michael. Sharing Responsibility: The German Federal Court of Justice and the Civil Appellate System, in Hurtado, Pablo (Ed.) Overburdened Supreme Courts:Transplanting Solutions? London: Springer, 2017.

TARUFFO, Michele. La motivazione della sentenza civile, Padova: Cedam, 1975.

TIDMARSH, Jay. The Future of Oral Argument, Loyola University Chicago Law Journal, Vol. 48, p. 475 486, 2016.

TROCKER, Nicoló; VARANO, Vicenzo. The Reforms of Civil Procedure in Comparative Perspective. Torino: Giappichelli Editore, 2005.

TRONSON, Brenda. Towards Proportionality - The "Quick, Cheap and Just” Balance in Civil Litigation, in Picker, C; Seidman, G., The Dynamisme of Civil Procedure-Global Trends and Developments, London: Springer, p. 183-202, 2016.

TURNER, Robert. The Proactive Judge and the Provision of a Single Transnational Case Management System and its Associated Procedures, in Andenas, M.; Andrews, N.; Nazzini, R. (Eds.), The future of Transnational Civil Litigation, London: The British Institute of International and Comparative Law, p. 73-88, 2004.

UNBERATH, Hannes. Der Zweck der Rechtsmittel nach der ZPO-Reform-Theorie und Praxis, Zeitschrift für Zivilprozessrecht, Vol. 120, n. 3, p. 323-346, 2007. 
van RHEE, Cornelis Hendrik (Remco). Introduction, in European Traditions in Civil Procedure. Antwerpen: Intersentia, p. 3-13, 2005.

VARGAS VIVANCOS, Juan Enrique; FUENTES MAUREIRA, Claudio. Régimen recursivo para la reforma a la justicia civil, in Leturia, Francisco (Ed.) Justicia civil y comercial. Una reforma ¿cercana?, Santiago de Chile: Libertad y Desarrollo, p. 343-355, 2011.

VESCOVI, Enrique. Los recursos judiciales y demás medios impugnatorios en Iberoamérica. Buenos Aires: Depalma, 1988.

VOIGT, Stephan. Determinants of Judicial Efficiency: a survey, European Journal of Law and Economics, Vol. 42, p. 183-208, 2016.

WAGNER, Gerhard. Ökonomische Analyse der Rechtsmittel, in Bork R.; Eger, T. (Coord.) Ökonomische Analyse desVerfahrenrechts, Tübingen: Mohr Siebeck, p. 157-193, 2009.

WALLACE, J. Clifford. Improving the Appellate Process Worldwide Through Maximizing Judicial Resources, Vanderbilt Journal of Transnational Law, Vol. 18, p. 187, 2005.

WILNER, Irving. Civil Appeals: Are They Useful in the Administration of Justice? The Georgetown Law Journal, Vol. 56, p. 417, 1968.

ZUCKERMAN, Adrian. Litigation Management Under the CPR: A Poorly-Used Management Infrastructure, in The Civil Procedure Rules TenYears On, London: Deirdre Dwyer ed., 2009.

\section{COMO CITAR ESTE ARTIGO:}

RAGONE, Alvaro Javier Pérez. Hacia una apelación óptima: acceso y gerenciamiento de la segunda instancia. Revista Direito GV, v. 15, n. 3, 2019, e1927. doi: http://dx.doi.org/ 10.1590/2317-6172201927.
Alvaro Javier Pérez Ragone

Profesor de Derecho Procesal Civil en la Universidad Católica del Norte, Antofagasta, Chile. Profesor en la Universidad San Pablo-T, Tucumán, Argentina. Abogado (Universidad Nacional de TuCumÁn/Argentina), LL.M Y Doctor en DERECho pOR LA Universität ZU KöLn (Alemania). Postdoctorado en Derecho como Alexander-Von-Humboldt Fellow Universidad Freiburg (Alemania). Miembro del Instituto IBEROAMERICANo de DeRECho PROCESAL Y MIEMBRo de la Asociación Internacional de Derecho Procesal. alvaro.perez01ducn.cl 